\title{
ELECTROCRYSTALLIZATION OF CADMIUM ON COPPER SINGLE CRYSTAL PLANES UNDER THE INFLUENCE OF AN ASYMMETRIC ALTERNATING CURRENT
}

\author{
M.F. AHMED and F. PUSHPANADEN \\ Department of Chemistry, Central College, Bangalore University, Bangalore 560001, India.
}

Received 14 February 1977; revised manuscript received 5 May 1977

Cadmium grows with a $\{0001\}$ preferred orientation when electrodeposited on copper single crystals with pure dc. Superimposed alternating current in suitable ratios with dc perfects the $\{0001\}$ orientation in cadmium deposits. The snowflake dendritic growth produced in cadmium deposits under the influence of superimposed ac of a higher magnitude appears to initiate at the corners of hexagonal platelets. This is probably due to the re-entrancies created by rotation induced twinning of the hexagonal platelets.

\section{Introduction}

Use of alternating current in deposition technology is a familiar method of improving deposit characteristics [1]. Deposit characteristics like grain size, brightness, hardness etc., are shown to be influenced favourably by superimposing ac during deposition [2-4]. Morphological studies have been made in our laboratory of lead and zinc deposits $[5,6]$ produced on copper single crystal substrates under the influence of superimposed ac. These studies revealed that with suitable ratios of ac to dc, the compact deposits obtained are superior in quality with respect to characteristics like brightness, definition of growth features and epitaxy as compared to deposits obtained with pure dc. Further, with the knowledge that superimposed ac retards dendritic growth [7], the dendrite initiation stage of zinc was arrested by superimposing ac during zinc deposition. It was found that zinc dendrites emanate from tips of pyramids and that spirals are the dendrite precursors, as proposed by Diggle et al. [8].

In the light of these effects of superimposed ac on the morphology, a study was made on the morphological characteristics of cadmium-deposits by depositing them on copper single crystals with pure dc and superimposed ac. The results of the study are presented in this paper. The growth of cadmium with a definite orientation in the initial stages of deposition on copper single crystal planes has been reported by Satoshi et al. [9]. The electrolytic dendritic growth of cadmium was studied by Wranglen [10], who found it to grow as single crystals by a sequential layer growth mechanism involving two-dimensional nucleation for each layer. Price [11], in a study on vapour-grown cadmium dendrites, reported that the growth occurs at re-entrancies produced by twinning.

The orientations predicted in cadmium-deposits on the basis of microscopically observed growth morphological features in the present study could not be ascertained using electron diffraction or other techniques because of the lack of such equipment in our lab. The main intention has been to show the influence of superimposed ac on the morphology and this has been amply provided by the microphotographs.

The experiments were carried out systematically on the (111), (100) and (110) planes of copper. The results obtained were similar. Hence while reporting the results, no specific plane has been mentioned and only a general mention of copper single crystals is made by which is implied the (111), (100) and (110) faces of copper.

\section{Experimental}

A high voltage battery was used as a constant dc source. Alternating current $(50 \mathrm{~Hz})$ drawn from mains with suitable adjustments to maintain a gal- 
vanostatic condition was superimposed on $\mathrm{dc}$ by means of a circuit described earlier [12]. The effect of current with an anodic component $\left(I_{\mathrm{ac}}>I_{\mathrm{dc}}\right)$ was only investigated since the rippling current $\left(I_{\mathrm{ac}}<I_{\mathrm{dc}}\right)$ and pulsating current $\left(I_{\mathrm{ac}}=I_{\mathrm{dc}}\right)$ showed no substantial effect on the electrocrystallization of cadmium. The ac current densities were calculated from the absolute values of the strength of the current passing through the cell. The preparation of the cathode surface and general experimental procedure have been described elsewhere [13].

An acid cadmium perchlorate bath of composition $0.25 \mathrm{M} \mathrm{Cd}\left(\mathrm{ClO}_{4}\right)_{2}+0.1 \mathrm{M} \mathrm{HClO}_{4}$ was used to deposit cadmium on copper single crystal planes. A deposit thickness of $3.36 \mu \mathrm{m}$ was maintained constant before dendrite initiation in the deposit by chosing a time to pass the current equivalent to $5 \mathrm{C} / \mathrm{cm}^{2}$. After the initiation of dendrites, the deposition time was chosen at random. The cathodes were removed after deposition without switching off the current and washed well with conductivity water and dried with ethanol. The surface of the deposits was examined microscopically and the results microphotographed. Each experiment was repeated to ensure reproducibility. All the experiments were carried out at the laboratory temperature.

\section{Results and discussion}

Cadmium was deposited onto copper single crystal planes (111), (100) and (110). The morphology of the cadmium deposits obtained on these three planes, in the range of current densities studied and the experimental conditions employed, was virtually the same. The common morphology in compact cadmium deposits obtained with pure $\mathrm{dc}$ on the different planes was of layer type, but the compact deposits obtained under the influence of superimposed ac on the different planes exhibited a variety of hexagonal growth morphological features. Ridge growth, which is a characteristic epitaxial morphology of a (110) orientation in the fcc system, was not observed in cadmium deposits on copper (110) plane. Further, the cadmium desposited on polycrystalline copper substrates under the same experimental conditions produced a morphology similar to that observed on the oriented copper substrates. These observations reveal the lack of any epitaxial influence of oriented copper substrates on the cadmium deposits and also show an inclination of cadmium to grow with a $\{0001\}$ preferred orientation on copper substrates. The only justification, therefore, for the use of single crystals in the present study is the good reproducibility of results obtained on the oriented crystals.

The sequence of the morphological features observed in cadmium deposits on copper single crystals with increasing magnitudes of pure $\mathrm{dc}$ is as follows:

At low dc densities $\left(1-5 \mathrm{~mA} / \mathrm{cm}^{2}\right)$, cadmium deposited as hexagonal blocks sparsely covering the substrate surface in the form of islands (fig. $1 \mathrm{ob}$ served at a dc density of $1 \mathrm{~mA} / \mathrm{cm}^{2}$ ). On increasing the magnitude of $d c$, the active area of the substrate surface increased, producing a dense growth of islands which eventually coalesced with one another (fig. 2 observed at a dc density of $10 \mathrm{~mA} / \mathrm{cm}^{2}$ ) and produced compact deposits at higher current densities (fig. 3 observed at a dc density of $20 \mathrm{~mA} / \mathrm{cm}^{2}$ ). A layer morphology characterized the compact deposits of cadmium. Gradually increasing the magnitude of $\mathrm{dc}$ density, a value was reached $\left(25 \mathrm{~mA} / \mathrm{cm}^{2}\right.$ in the present study) when the onset of dendritic growth in the deposits was indicated by a slow evolution of gas on the substrate and a sudden increase in the overpotential from the initial value of $50 \mathrm{mV}$ to a value $250 \mathrm{mV}$. The deposit on examination revealed classical two-dimensional dendrites in a background of compact deposit (fig. 4). Direct current densities exceeding this value produced thick dendritic sponge on the entire surface of the substrate (fig. 5 observed at a de density of $40 \mathrm{~mA} / \mathrm{cm}^{2}$ ).

The sequence in the morphology as observed followed the usual course, namely, sparse deposits produced at low dc densities leading to compact deposits at moderate values of $\mathrm{dc}$ densities and ultimately turning into non-compact deposits at high de densities. The morphology was not rich with respect to the variety of growth features. However, superimposed ac produced varied and interesting morphology in cadmium deposits on copper single crystals.

4. Morphology of compact cadmium desposits obtained under the influence of superimposed ac on copper single crystals

The compact cadmium deposits obtained with pure dc exhibited predominantly a layer morphology 


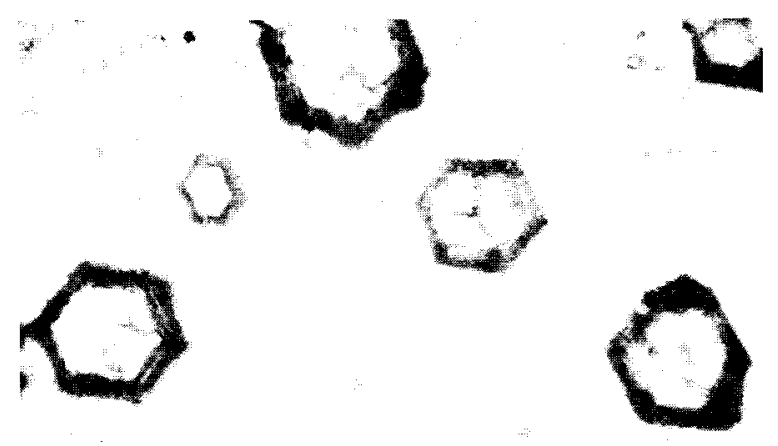

Fig. 1. Hexagonal block growth of cadmium on copper single crystals; c.d. $=1 \mathrm{~mA} / \mathrm{cm}^{2}$ dc. Magn. $\times 600$.

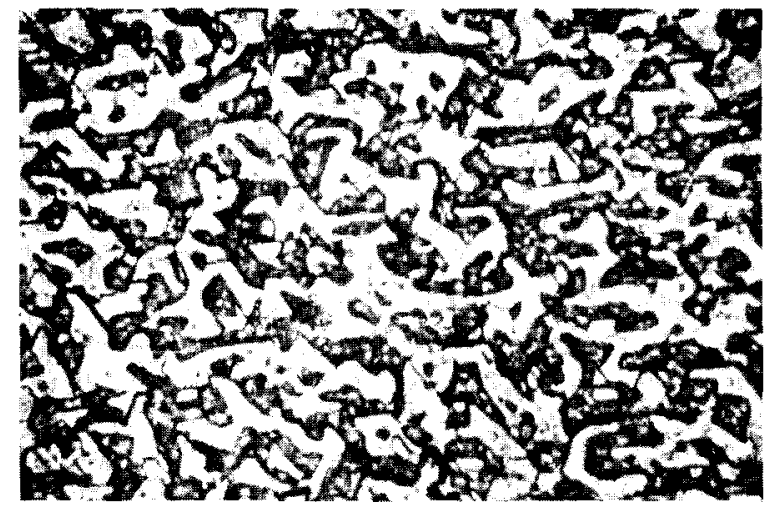

Fig. 2. Coalesced island growth of cadmium on copper single crystals; c.d. $=10 \mathrm{~mA} / \mathrm{cm}^{2}$ dc. Magn. $\times 600$.

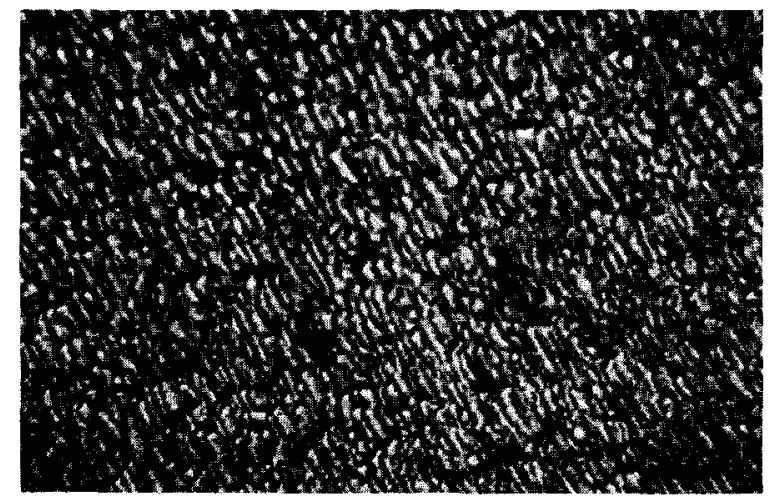

Fig. 3. Layer growth in compact deposits of cadmium on copper single crystals; c.d. $=20 \mathrm{~mA} / \mathrm{cm}^{2} \mathrm{dc}$. Magn. $\times 600$.

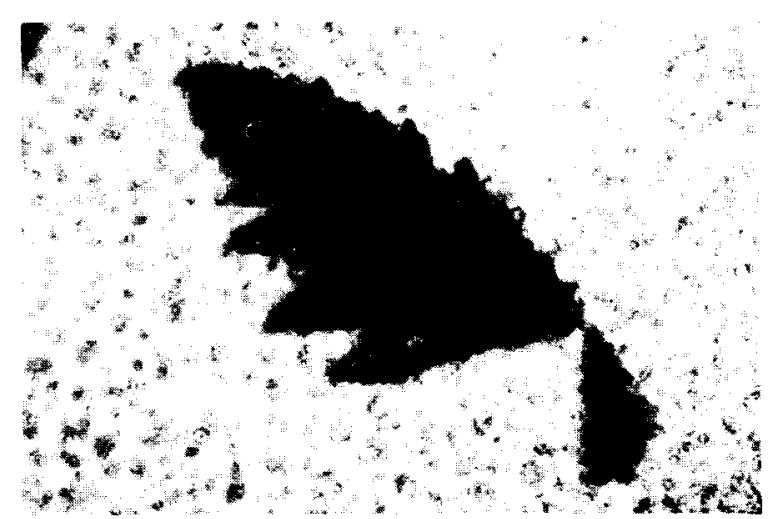

Fig. 4. Classical two-dimensional dendrites of cadmium on copper single crystals; c.d. $=25 \mathrm{~mA} / \mathrm{cm}^{2}$ dc. Magn. $\times 600$.

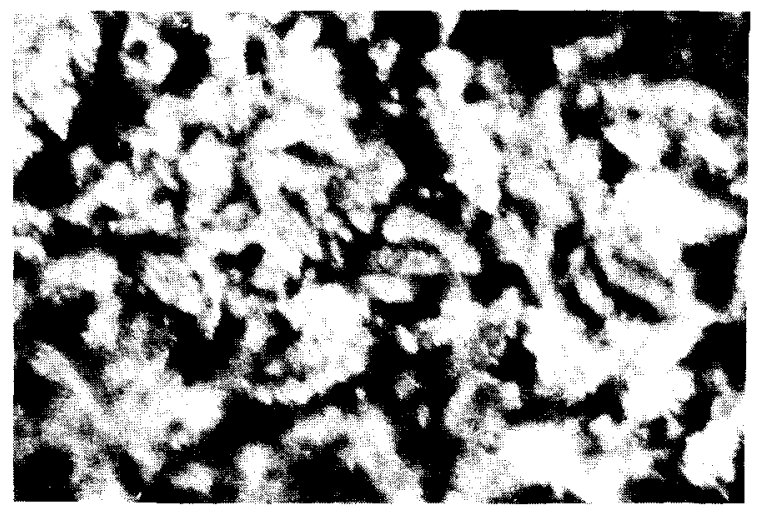

Fig. 5. Heavy dendritic sponge of cadmium on copper single crystals; c.d. $=40 \mathrm{~mA} / \mathrm{cm}^{2}$ dc. Magn. $\times 600$.

(cf. fig. 3 recorded at $20 \mathrm{~mA} / \mathrm{cm}^{2}$ dc). On superimposition of increasing magnitudes of ac on $20 \mathrm{~mA} /$ $\mathrm{cm}^{2} \mathrm{dc}\left(I_{\mathrm{ac}}\right.$ always greater than $\left.I_{\mathrm{dc}}\right)$ during deposition, the following morphological patterns developed in the deposits:

Hexagonal blocks in a smooth background (fig. 6, observed at $20 \mathrm{~mA} / \mathrm{cm}^{2} \mathrm{dc}+25 \mathrm{~mA} / \mathrm{cm}^{2}$ ac);

Hexagonal button growth (fig. 7, observed at $20 \mathrm{~mA} /$ $\left.\mathrm{cm}^{2} \mathrm{dc}+30 \mathrm{~mA} / \mathrm{cm}^{2} \mathrm{ac}\right)$;

Hexagonal flower growth (figs. 8a-8d, observed at $\left.20 \mathrm{~mA} / \mathrm{cm}^{2} \mathrm{dc}+30 \mathrm{~mA} / \mathrm{cm}^{2} \mathrm{ac}\right)$;

Hexagonal star growth (fig. 9 , observed at $20 \mathrm{~mA}$ / $\left.\mathrm{cm}^{2} \mathrm{dc}+30 \mathrm{~mA} / \mathrm{cm}^{2} \mathrm{ac}\right)$;

Hexagonal pyramidal growth (fig. 10 , observed at $20 \mathrm{~mA} / \mathrm{cm}^{2} \mathrm{dc}+35 \mathrm{~mA} / \mathrm{cm}^{2} \mathrm{ac}$ ); 


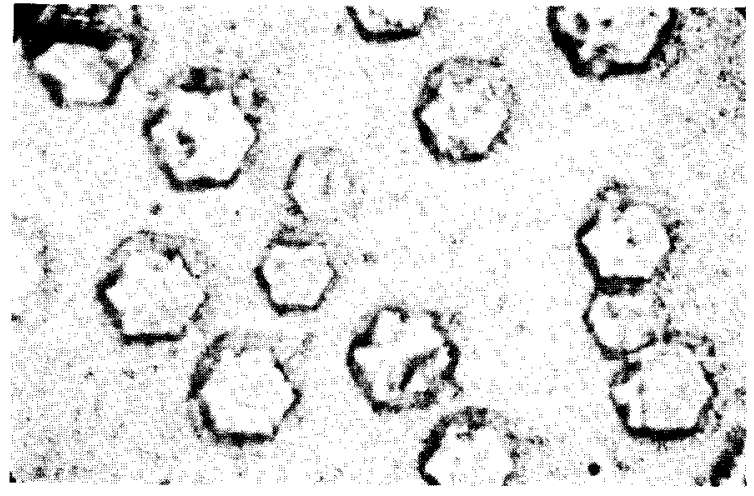

Fig. 6. Hexagonal blocks in a smooth background of cadmium deposits on copper single crystals; c.d. $=20 \mathrm{~mA} / \mathrm{cm}^{2}$ $\mathrm{dc}+25 \mathrm{~mA} / \mathrm{cm}^{2}$ ac.

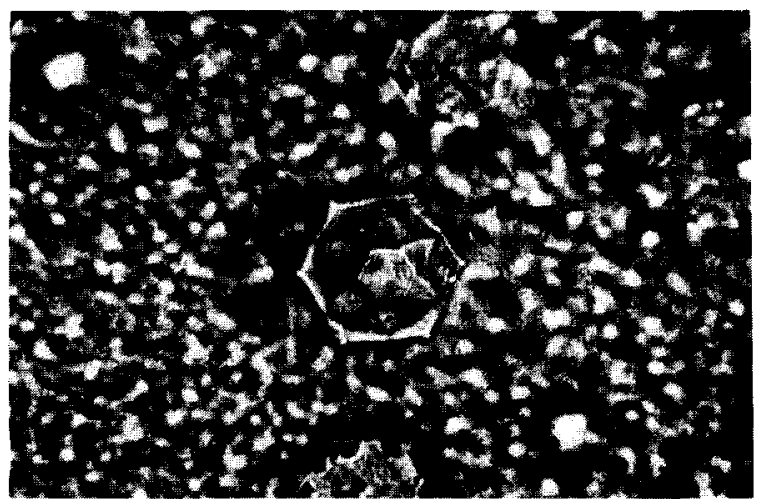

Fig. 7. Hexagonal button growth of cadmium on copper single crystals; c.d. $=20 \mathrm{~mA} / \mathrm{cm}^{2} \mathrm{dc}+30 \mathrm{~mA} / \mathrm{cm}^{2} \mathrm{ac}$.

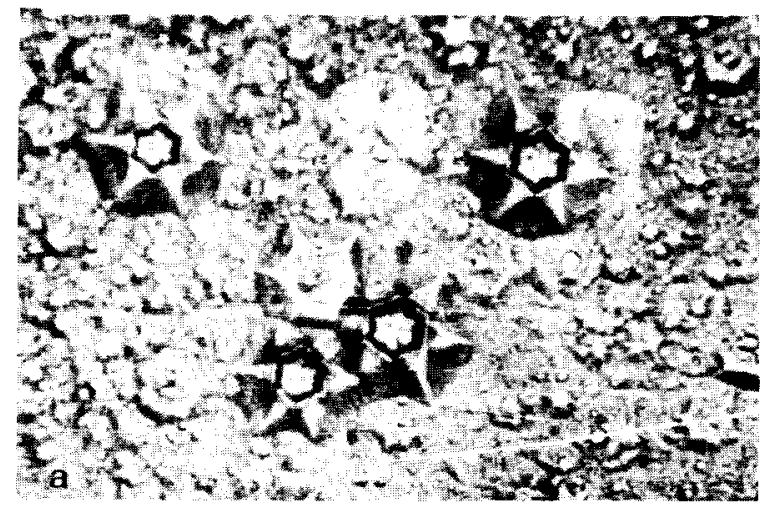

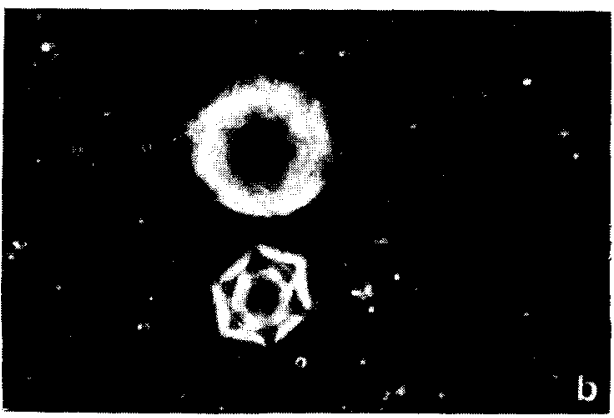
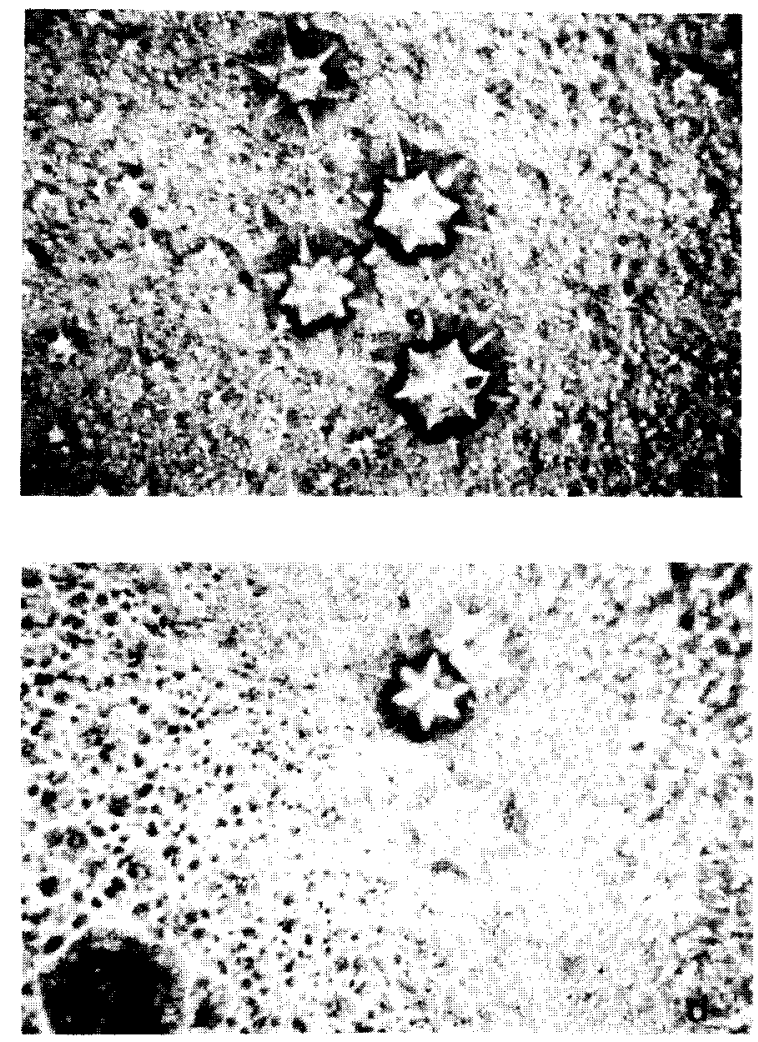

Fig. 8. Hexagonal flower growth of cadmium on copper single crystals; c.d. $=20 \mathrm{~mA} / \mathrm{cm}^{2} \mathrm{dc}+30 \mathrm{~mA} / \mathrm{cm}^{2}$ ac.

Network of hexagonal platelets (figs. 11 and 12 observed at $20 \mathrm{ma} / \mathrm{cm}^{2} \mathrm{dc}+40 \mathrm{~mA} / \mathrm{cm}^{2}$ ac and $20 \mathrm{~mA} /$ $\mathrm{cm}^{2} \mathrm{dc}+45 \mathrm{~mA} / \mathrm{cm}^{2}$ ac respectively);

Lumps of deposit (fig. 13 observed at $20 \mathrm{~mA} / \mathrm{cm}^{2} \mathrm{dc}$ $\left.+50 \mathrm{~mA} / \mathrm{cm}^{2} \mathrm{ac}\right)$.

On the basis of microscopically observed growth morphological features described above, it is inferred 


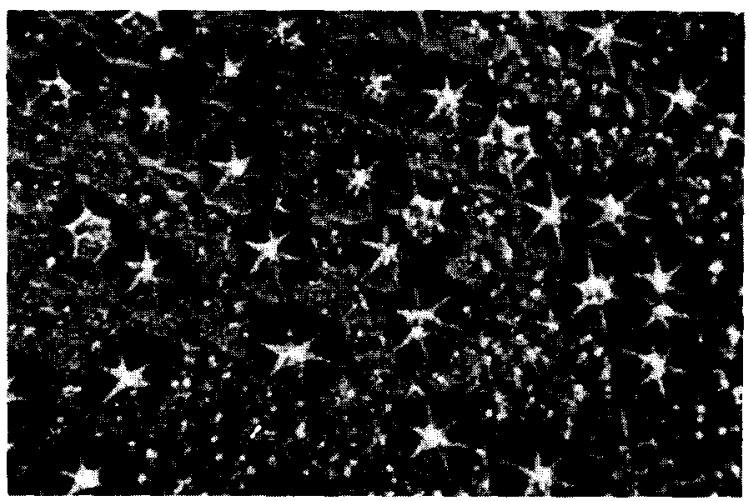

Fig. 9. Hexagonal star growth of cadmium on copper single crystals; c.d. $=20 \mathrm{~mA} / \mathrm{cm}^{2} \mathrm{dc}+30 \mathrm{~mA} / \mathrm{cm}^{2}$ ac.

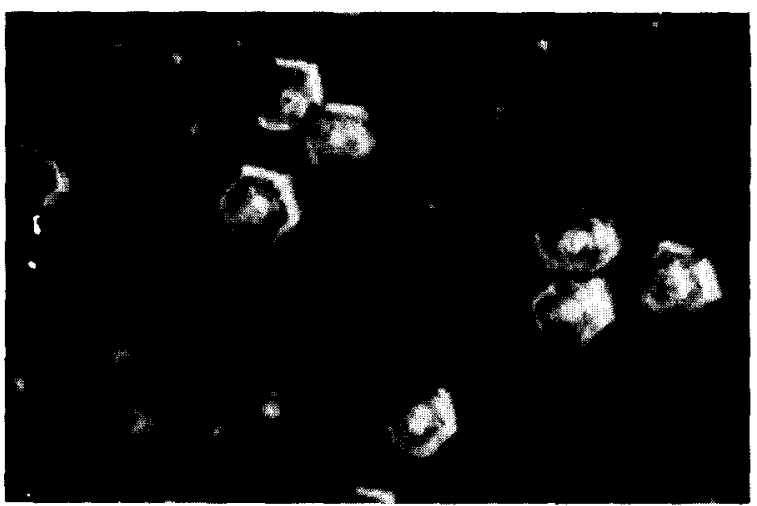

Fig. 10. Hexagonal pyramidal growth of cadmium on copper single crystals; c.d. $=20 \mathrm{~mA} / \mathrm{cm}^{2} \mathrm{dc}+35 \mathrm{~mA} / \mathrm{cm}^{2} \mathrm{ac}$.

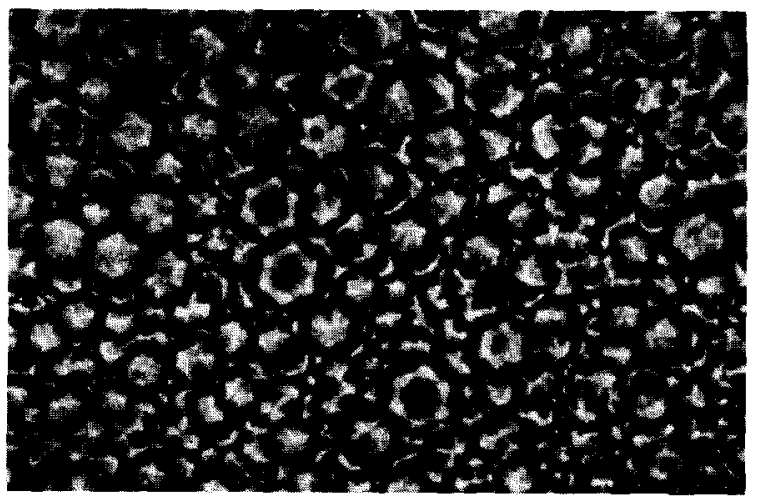

Fig. 11. Network of hexagonal platelets of cadmium on copper single cry stals; c.d. $=20 \mathrm{~mA} / \mathrm{cm}^{2} \mathrm{dc}+40 \mathrm{~mA} / \mathrm{cm}^{2}$ ac.

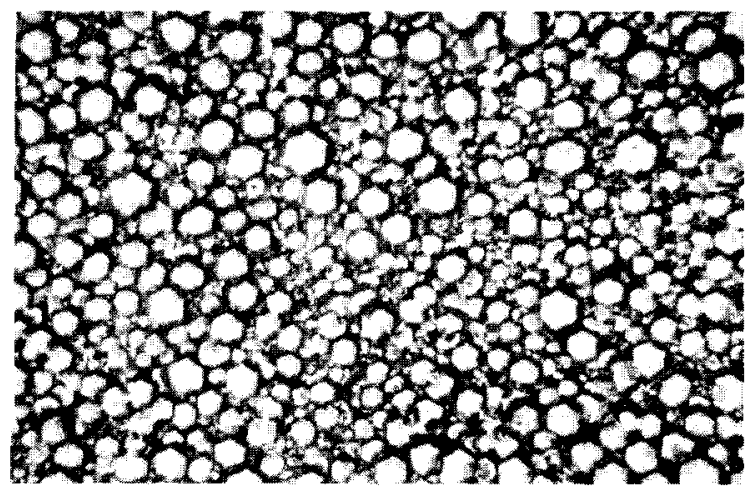

Fig. 12. Network of hexagonal platelets of cadmium on copper single crystals; c.d. $=20 \mathrm{~mA} / \mathrm{cm}^{2} \mathrm{dc}+45 \mathrm{~mA} / \mathrm{cm}^{2}$ ac.

that the hexagonal blocks and compact deposits with a layer morphology resulting from their coalescence are suggestive of a preferred $\{0001\}$ orientation in cadmium deposits obtained with pure dc. Cadmium being a hcp metal, the $\{0001\}$ orientation in compact cadmium deposits (lateral growth) would be more clearly represented by hexagonally shaped growth features. we have observed a variety of hexagonal growth features in cadmium deposits obtained under the influence of superimposed ac. Hence it is inferred that the $\{0001\}$ orientation in cadmium deposits is perfected under the influence of superimposed ac. Superimposed ac, however, is beneficial only in a certain range. Higher magnitudes (magnitude in relation

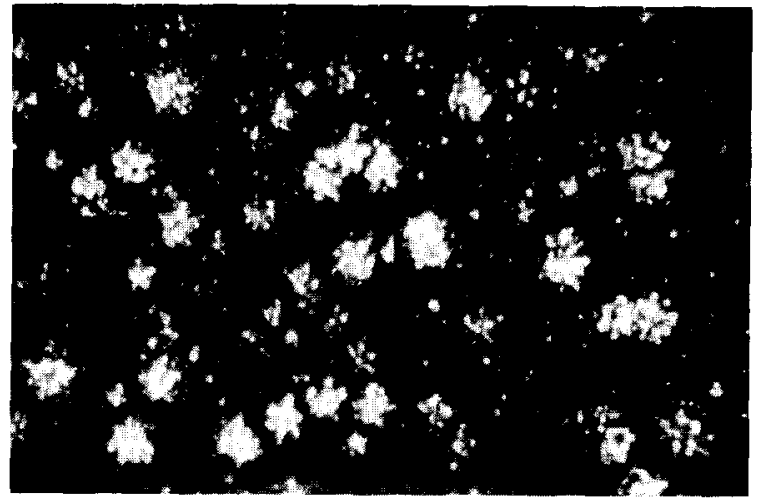

Fig. 13. Distorted growth in cadmium deposits on copper single crystals; c.d. $=20 \mathrm{~mA} / \mathrm{cm}^{2} \mathrm{dc}+50 \mathrm{~mA} / \mathrm{cm}^{2} \mathrm{ac}$. 
tocurrent density) of superimposed ac have a deteriorating effect on the morphology, as seen in fig. 13 . Superimposed ac is considered to effect these changes in the deposits by virtue of its anodic component. The anodic cycle is accompanied by a current reversal and hence dissolution. A constant recurrence of this process at regular intervals during the course of deposition with superimposed ac serves as a cleansing agent and produces bright and clean deposits. Superimposed ac also has a slight depolarizing effect. In suitable ratios of ac to dc, this probably improves the conditions for cadmium to nucleate and grow predominantly with a $\{0001\}$ preferred orientation.

5. Snowflake dendritic growth of cadmium on copper single crystals obtained under the influence of superimposed ac

The appreance of dendrites is considered to be due to a slow supply of depositing ions to the cathode. Such a condition of depletion of ions at the cathode were set in at a dc density of $25 \mathrm{~mA} / \mathrm{cm}^{2}$ in the bath used for deposition of cadmium in the present study. The deposits obtained at this current density exhibited classical two-dimensional dendrites in a background of compact deposit (cf. fig. 4). The growth of dendrites is a very fast process. Hence it was not possible to observe the initiation of dendrites even with very short time of deposition. However, it has been suggested [7] that by providing some relaxation time in the system in the form of current interruption or reversal, the supply of ions to the cathode could be made more efficient and dendritic growth thereby controlled. Utilizing this fact, ac was superimposed at the moment of dendrite initiation and this enabled us to record the dendrite initiation stage. The deposits obtained after one minute of deposition with $25 \mathrm{~mA} /$ $\mathrm{cm}^{2} \mathrm{dc}+50 \mathrm{~mA} / \mathrm{cm}^{2}$ ac revealed hexagonal platelets and snowflake dendrites in different stages of growth (figs. 14a, b, c). The snowflake dendrites appear to initiate at the corners of hexagonal platelets. The snowflake dendrite initiation and growth as observed is more clearly shown schematically in fig. 16 . With prolonged deposition at the same ac/dc ratio, the initiation stage of dendrites was obliterated and fully grown hexagonal star dendrites appeared in the
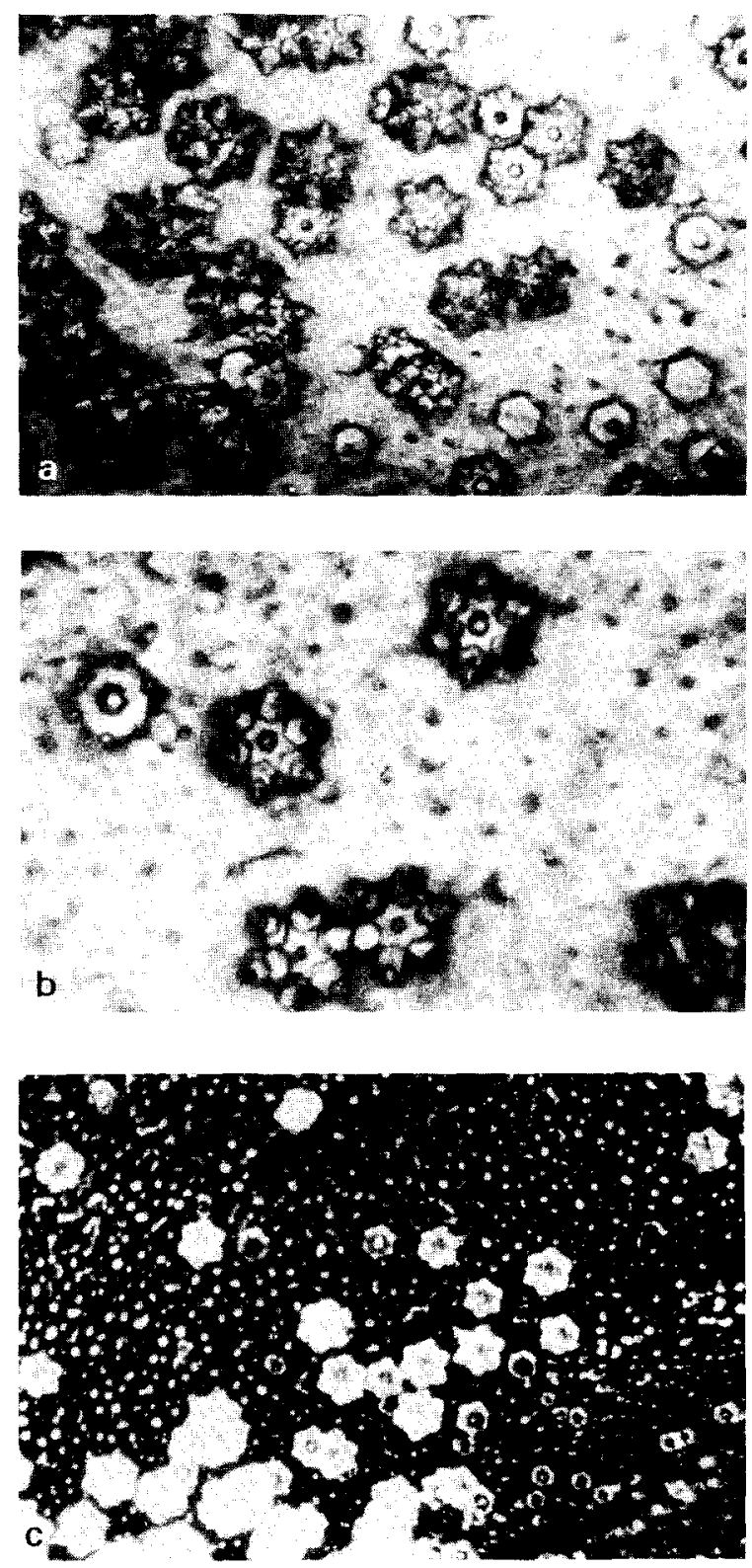

Fig. 14. Cadmium snowflakes dendrites on copper single crystals; c.d. $=25 \mathrm{~mA} / \mathrm{cm}^{2} \mathrm{dc}+50 \mathrm{~mA} / \mathrm{cm}^{2}$ ac (time of deposition is $1 \mathrm{~min}$ ).

deposit (fig. 15 observed after five minutes of deposition).

Screw dislocations and separation planes in twinning (re-entrancies) are considered to be two particularly favourable sites for the crystal lattice extension 


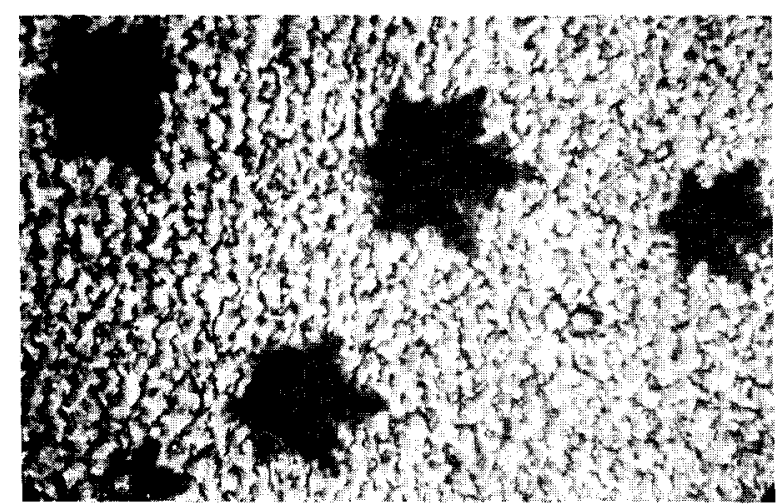

Fig. 15. Hexagonal star dendrites of cadmium on copper single crystals; c.d. $=25 \mathrm{~mA} / \mathrm{cm}^{2} \mathrm{dc}+50 \mathrm{~mA} / \mathrm{cm}^{2}$ ac (time of deposition is $5 \mathrm{~min}$ ).

in a dendrite. This is in accordance with the principle of minimum energy of formation for nucleation applied to a crystal building process $[14,15]$. That the reentrancies are responsible for dendritic growth in cadmium has been clearly substantiated by Price [11] with his study on vapour-grown cadmium leaf dendrites. According to his observations, parallel growth twins formed at the rotation boundary of the

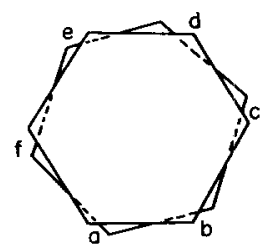

(A) $a, b, c, d, e, f=$ Re-entrant edges

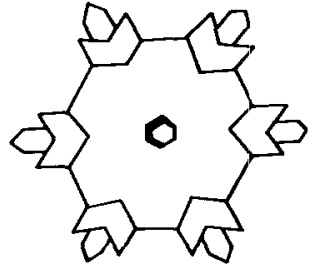

(c)

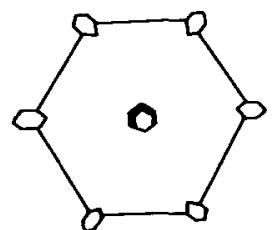

(B)

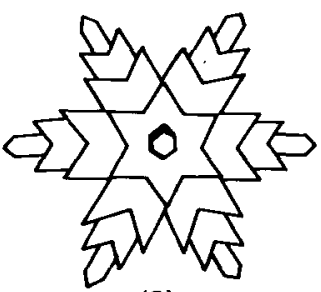

(D)
Fig. 16. Schematic representation of the different stages in the formation of cadmium snowflake dendrites. rotated crystals, grow into leaf dendrites. These possess (0001) composition plane and a stalk which is the [1230] twin axis. A similar twinning mechanism seems to operate in the snowflake dendritic growth of cadmium observed in the present study. The hexagonal platelets probably have their upper layers rotated with respect to those below them, producing re-entrancies at the corners as shown in fig. 16 . The re-entrancies at these positions are the site of easy nucleation and growth. Hence the hexagonal platelets grow into snowflake cadmium dendrites.

\section{Acknowledgments}

The authors thank Dr. M. Shadaksharaswamy, Head of the Department of Chemistry, Central College, Bangalore, for providing laboratory facilities and Dr. B.S. Sheshadri for helpful discussions. One of the authors (M.F.A.) thanks CSIR, New Delhi, for financial assistance in the form of SRF.

\section{References}

[1] A.T. Vagramyan and Z.A. Soleveva, Technology of Electrodeposition (Robert Draper, Teddington, 1961) p. 95.

[2] A.T. Vagramyan and A.A. Sutyagina, Izv. Akad. Nauk SSSR, Otd. Khim. Nauk 3 (1952) 30.

[3] V.J. Marchese, J. Electrochem. Soc. 99 (1952) 39.

[4] Z. Kovac, J. Electrochem. Soc. 118 (1971) 51.

[5] M.F. Ahmed, B.S. Sheshadri and F. Pushpanaden, J. Electrodepos. Surface Treat. 3 (1975) 65.

[6] M.F. Ahmed, B.S. Sheshadri and F. Pushpanaden, J. Mater. Sci. 12 (1977) 549.

[7] V.V. Stender and M.D. Zholuv, Zh. Prikl. Khim. 32 (1959) 1296.

[8] J.W. Diggle, A.R. Despic and J.O'M. Bockris, J. Electrochem. Soc. 116 (1969) 1503.

[9] Itoh Satoshi, Nakamura Yoshito, Okada Genji and Seiyama Tetsuro, Denki Kagaku Oyobi Kogyo Butsuri Kagaku 42 [7] (1974) 365.

[10] G. Wranglen, Electrochim. Acta 2 (1960) 130.

[11] P.B. Price, Phil. Mag. 4 (1959) 1229.

[12] B.S. Sheshadri and T.H.V. Setty, J. Crystal Growth 21 (1974) 110.

[13] B.S. Sheshadri and T.H.V. Setty, Indian J. Chem. 8 (1970) 167.

[14] N.A. Pangarov and V. Velinov, Electrochim. Acta 13 (1968) 1909.

[15] N.A. Pangarov, Electrochim. Acta 9 (1964) 721. 